\title{
Advances and Current Challenges in Marine Biotoxins Monitoring
}

\author{
Pedro Reis Costa \\ IPMA-Portuguese Institute of the Sea and Atmosphere, Av. Alfredo Magalhães Ramalho 6, \\ 1495-165 Lisbon, Portugal; prcosta@ipma.pt
}

Received: 23 August 2019; Accepted: 30 August 2019; Published: 2 September 2019

Shellfish are filter-feeding organisms that may accumulate high levels of naturally-occurring toxins, produced by harmful algal blooms, and act as marine toxin vectors to whomever consumes them. In order to protect public health, most coastal countries and particularly countries with shellfish production areas must have an effective monitoring in place to minimize the risk of acute intoxications and to warranty the quality of the seafood products. The decade of 2010-2019 that is rapidly approaching its end is going to be characterized by four categories of challenges that scientific communities and agencies with responsibilities in terms of seafood safety had to deal with: i) emergence of new toxins, ii) identification of new analogues of regulated toxins, iii) moving away from biological methods for official control and, iv) harmonization of detection methods and regulatory limits in a world of global trade.

Changes in climate conditions, anthropogenic activities and technological advance are commonly pointed out to justify the increasing occurrence, frequency and intensity of harmful algal blooms and the detection of new toxins or emergence of toxins in regions where they were previously not known. Toxins endemic from (sub)tropical regions have been found in temperate waters, causing human outbreaks due to consumption of contaminated seafood, including species other than bivalves mollusks, such as gastropods and fish.

Technological advance for sensitive and accurate sophisticated detection methods is needed, but also cost effective and fast, high-throughput, in situ, real-time monitoring, semi-quantitative or qualitative, or technically less complex are important to respond to the challenges posed by the new and emerging toxins. Moving away from biological into more sensitive and selective methods has been giving room to better understand the toxins dynamics of accumulation/transformation/elimination throughout the marine organisms in the food chain and therefore to assess the risk for human consumption of the wide range of seafood species.

The four papers published in this Special Issue initiated a forum on Journal of Marine Science and Engineering about marine biotoxins, challenges and advances in their detection and monitoring, new toxins and new toxin vectors. Lopes et al. [1] reported the first steps to estimate toxic phytoplankton cell abundances and toxin levels in seawater based on modeling spectral data recorded by Fourier Transform Near Infrared Spectroscopy. Novoveská and Robertson [2] by identifying spherical cells, most likely a morphological stage of the toxin-producing dinoflagellate Karenia brevis, as a source of brevetoxins in Mobile Bay, Gulf of Mexico, USA, suggesting that monitoring programs relying only on microscopy are not sufficient to properly evaluate the risk and that data on toxin occurrence is needed. Similarly, Loeffler et al. [3] highlighted the importance of determining the toxin content, in this case regarding ciguatoxins, and not relying only on species identification, in this case fish species that are commonly recognized as toxin vectors. In their work, Loeffler and colleagues [3] revealed the presence of C-CTX-1 in a hybrid between a local commercially prized species Ocyurus chrysurus (male) and a regionally prohibited species Lutjanus apodus (female), collected from nearshore US Virgin Islands waters. Finally, Rodrigues et al. [4] reported the first study investigating the presence of tetrodotoxin 
(TTX) and TTX analogues in bivalve mollusks from the Portuguese coast. TTX is a potent neurotoxin, traditionally known in Asian countries such as Japan, that has been receiving particular attention in Europe.

Acknowledgments: Gratitude is due to all contributing authors and reviewers.

Conflicts of Interest: The author declares no conflict of interest.

\section{References}

1. Lopes, M.B.; Amorim, A.; Calado, C.; Reis Costa, P. Determination of Cell Abundances and Paralytic Shellfish Toxins in Cultures of the Dinoflagellate Gymnodinium catenatum by Fourier Transform Near Infrared Spectroscopy. J. Mar. Sci. Eng. 2018, 6, 147. [CrossRef]

2. Novoveská, L.; Robertson, A. Brevetoxin-Producing Spherical Cells Present in Karenia brevis Bloom: Evidence of Morphological Plasticity? J. Mar. Sci. Eng. 2019, 7, 24. [CrossRef]

3. Loeffler, C.R.; Handy, S.M.; Flores Quintana, H.A.; Deeds, J.R. Fish Hybridization Leads to Uncertainty Regarding Ciguatera Fish Poisoning Risk; Confirmation of Hybridization and Ciguatoxin Accumulation with Implications for Stakeholders. J. Mar. Sci. Eng. 2019, 7, 105. [CrossRef]

4. Rodrigues, S.M.; Pinto, E.P.; Oliveira, P.; Pedro, S.; Costa, P.R. Evaluation of the Occurrence of Tetrodotoxin in Bivalve Mollusks from the Portuguese Coast. J. Mar. Sci. Eng. 2019, 7, 232. [CrossRef]

(C) 2019 by the author. Licensee MDPI, Basel, Switzerland. This article is an open access article distributed under the terms and conditions of the Creative Commons Attribution (CC BY) license (http://creativecommons.org/licenses/by/4.0/). 